\title{
Notas
}

\section{De nuevo sobre lo fantástico ${ }^{1}$}

\author{
REMO CESERANI*
}

\section{Resumen:}

En este artículo, Remo Ceserani, que en varias ocasiones ha trabajado ya acerca del modo fantástico y sus fronteras con otros modos o géneros literarios, se centra en cuatro puntos que lo conducen a una reflexión unificadora de lo fantástico. El primero es la cuestión terminológica que siempre es central en este asunto, ya que "fantástico" siempre plantea una serie de problemas pues se ha usado con matices de significado bastante diversos en varias lenguas europeas. Tras estos primeros desbroces, se emprende un trabajo de diferenciación entre el género y el modo de lo fantástico, que lo conduce a definir los modos como procedimientos retóricos-formales, actitudes cognoscitivas y agregaciones temáticas, que pueden ser utilizables por varios códigos, géneros y formas en la realización de los textos literarios. Finalmente, el trabajo se aboca a investigar el porqué de la falta de textos italianos fantásticos y en la reflexión sobre lo moderno y lo posmoderno del modo fantástico que, en varios escritores que desglosan lo fantástico clásico y lo reformulan desde una perspectiva diferente, da como resultado un neo-fantástico o fantástico revisitado.

\section{Palabras clave:}

Fantástico, neo-fantástico, diferencia entre géneros y modos, teorías de lo fantástico.

\footnotetext{
${ }^{1}$ Traducción del italiano de Claudia Magos, revisada por J. M. Sardiñas.

${ }^{*}$ Universitá di Bologna.
} 
Del modo fantástico y sus fronteras con otros modos o géneros literarios me he ocupado en varias ocasiones en el pasado (Ceserani 1983 y 1986). Me centraré aquí en cuatro puntos que considero merecen una reflexión colectiva.

\section{La cuestión terminológica}

Todos sabemos que el término "fantástico" plantea una serie de problemas. Se ha usado con matices de significado bastante diversos en las varias lenguas europeas. Su uso en literatura se enreda inevitablemente, creando complicaciones no fáciles de resolver, con usos muy precisos y técnicos, propios del lenguaje psicológico y filosófico. También en literatura, ha operado históricamente con significados a menudo muy diversos, aun cuando hubo un periodo, en el curso del siglo xix, sobre todo en Alemania y en Francia, en el que los escritores, cuando daban un título a sus narraciones usando términos como Fantasiestücke o Contes fantastiques, o escribían una introducción a una colección suya o una reseña a una obra ajena hablando de fantastique, hacían una selección muy distante de ser casual. Advertían que practicaban un género literario nuevo y original.

Es inútil que vuelva a hablar aquí de los enredos terminológicos que se han formado en la tradición crítica y de las contrastantes tendencias a utilizar el término en sentido restrictivo, refiriéndose a una tradición muy limitada y precisa que floreció sobre todo en el siglo XIx (es la posición de Todorov), o a utilizarlo en sentido amplio, e incluso amplísimo, extendiéndolo a géneros de literatura muy diversos como la fábula, el roman maravilloso, la fantasy o la ciencia ficción (por ejemplo, Schlobin, Bleiler, Jackson), llegando casi a hacer coincidir lo fantástico con toda producción literaria o poética.

Permítaseme dar un ejemplo, que me parece muy instructivo, de estas dificultades terminológicas y de los problemas que implican. Luigi Pirandello, en la presentación del importante ensayo L'umorismo, publicado en primera edición en 1908 y en segunda en 1920 (en Pirandello 15-179), al enfrentarse con la historia de la palabra "humorismo" y con el concepto o conceptos que ella designa, se halla, 
de pronto, significativamente (y de manera, creo, interesante también para nuestras discusiones), los términos "fantasía" y "fantástico", encontrados en un estudio de Alessandro D'Ancona (1880), sobre el poeta cómico sienés del siglo XIIICecco Angiolieri:

Del resto, poi, la nostra lingua ha umore per fantasia, capriccio, e umorista per fantastico: e gli umori dell'animo e del cervello ognun sa che stanno in stretta relazione con la poesia umorista. E l'Italia ebbe ai suoi tempi le accademie degli Umorosi a Bologna ed a Cortona e degli Umoristi in Roma, e speriamo che i mali umori della politica non le facciano mai venir meno i begli umori nel regno dell'arte. (Citado en Pirandello 17$)^{2}$

Pirandello, como D'Ancona, se refería, naturalmente, a la antigua teoría médica de los humores, aun estando consciente de que ninguno de los cuatro humores canónicos parecía tener ninguna relación con la ironía, la comicidad o el humorismo. Se refería, en todo caso y con buenas razones, a la melancolía, entendida como enfermedad y exceso de humor negro:

La parola umore derivò a noi naturalmente dal latino e col senso materiale che essa aveva di corpo fluido, liquore, umidità o vapore, e col senso anche di fantasia, capriccio o vigore. 'Aliquantum babeo bumoris in corpore, neque dum exarui ex amoenis rebus et voluptariis' (Plauto). Qui bumor non ha evidentemente senso materiale, perché sappiamo che, fin dai tempi più antichi, ogni umore nel corpo era ritenuto segno o cagione di malattia. [...] Sarà bene, trattando dell'umorismo, tener presente anche quest'altro significato di malattia della parola

\footnotetext{
2 "Por lo demás, nuestra lengua tiene humor para fantasía, capricho, y humorista para fantástico: y los bumores del ánimo y del cerebro, cada uno sabe que están en estrecha relación con la poesía bumorista. E Italia tuvo en su tiempo las academias de los Humorosos en Bologna y en Cortona y de los Humoristas en Roma; y esperamos que los malos humores de la política no hagan venir a menos los bellos bumores del reino del arte."
} 
umore, e che malinconia, prima di significare quella delicata affezione o passion d'animo che intendiamo noi, abbia avuto in origine il senso di bile o fiele e sia stata per gli antichi un umore nel significato materiale della parola. ${ }^{3}(17-18)$

Pirandello, probablemente, no conocía la tradición derivada del Pseudo-Aristóteles y de la teoría renacentista de Marsilio Ficino y de tantos otros, que relacionaba el exceso de humor negro (la melancolía) con la actividad intelectual y la creación artística, sobre la base de la idea de que la excitación, el fervor creativo, el furor poético, y tal vez la ebriedad, tuvieran la capacidad de calentar el humor negro, por naturaleza frío, duro, saturnino, permitiéndole desfogarse en la extravagancia, en el capricho y en el desorden de la actividad intelectual, en el estro genial, podríamos decir en el humorismo fantástico.

Y, sin embargo, Pirandello llegó, sin necesidad de apoyarse en aquella tradición, o apoyándose en las últimas derivaciones tardorománticas de ella, a las mismas conclusiones.

Él, de hecho, no sólo ha sostenido, como han hecho y harán tantos intérpretes y estudiosos de la actividad intelectual y creativa, de Benjamin a Starobinski, que todos los intelectuales y artistas modernos son inevitablemente melancólicos y espíritus críticos y fantásticos, "nacidos bajo Saturno" (Sontag), sino que ha llegado tranquilamente a utilizar el término "fantástico" para definir toda

3 “La palabra humor [umore] llegó a nosotros naturalmente del latín y con el sentido material que tenía de cuerpo fluido, líquido, humedad o vapor; y con el sentido también de fantasía, capricho o vigor. 'Aliquantum babeo bumoris in corpore, neque dum exarui ex amoenis rebus et voluptariis' (Plauto). Aquí bumor no tiene evidentemente sentido material, porque sabemos que, desde de los tiempos más antiguos, cada humor en el cuerpo era considerado señal o causa de enfermedad. [...] Será bueno, tratando del humorismo, tener presente también este otro significado de enfermedad de la palabra humor, y que melancolía, antes de significar la delicada afección o pasión de ánimo que entendemos nosotros, había tenido en sus orígenes el sentido de bile o fiele y había sido para los antiguos un humor en el significado material de la palabra." 
su actividad creadora ${ }^{4}$ y ha basado en la relación entre humorístico y fantástico su misma teoría del arte y su misma concepción de la vida, en el centro de las cuales ha puesto la que llamó, precisamente, el "sentimiento del contrario", es decir, la reacción distanciada e irónica ante las penas de la existencia:

Ogni vero umorista non è soltanto poeta, è anche critico, ma -si badi- un critico sui generis, un critico fantastico: e dico fantastico non solamente nel senso di bizzarro o di capriccioso, ma anche nel senso estetico della parola, quantunque possa sembrare a prima giunta una contradizione in termini. Ma è proprio così; e però ho sempre parlato di una speciale attività della riflessione. [...] La riflessione [...] di cui io parlo non è un'opposizione del cosciente verso lo spontaneo; è una specie di projezione della stessa attività fantastica: nasce dal fantasma, come l'ombra dal corpo; ha tutti i caratteri della 'ingenuità' o natività spontanea; è nel germe stesso della creazione, e spira in fatti da essa ciò che ho chiamato il sentimento del contrario. ${ }^{5}(133-134)$

De estas citas de Pirandello, que pueden quizá parecer peregrinas -pero pienso que no lo son-, creo que se pueden extraer algunas reflexiones de importancia:

a) Ofrecen un ejemplo posterior de las dificultades terminológicas en las que nos debatimos cada vez que nos ocupamos del modo fantástico. Esto parece tener un núcleo duro originario, que lo ubica en un momento histórico preciso, el del verdadero y propio "descubrimiento" de una modalidad nueva en el imaginario literario, ocurrido entre finales del siglo XVIII y prin-

${ }^{4}$ Así en uno de los llamados "folletos" editados en 1934 por Corrado Alvaro (Pirandello 1259): "De toda mi obra fantástica, se puede deducir el modo particular que siempre he tenido de considerar el mundo y la vida."

5 "Todo humorista verdadero no sólo es poeta, es también crítico, pero -téngase en cuenta- un crítico sui generis, un crítico fantástico: y digo fantástico no solamente en el sentido de extravagante o de caprichoso, sino también en el sentido estético de la 
cipios del XIX, y de la fundación de un nuevo género, relacionado con el "gótico", sin embargo, diferente de él. No obstante, su mismo origen, coincidente con la reestructuración general de los géneros y modos acaecida en aquella época, y la carga de ambigüedad y complejidad semántica que llevan consigo términos como fantasma, fantasía y fantástico explican el continuo deslizamiento posterior del término, y su extensión y aplicación a las más diversas modalidades literarias, hasta casi coincidir (como sucede también en Pirandello) con toda una producción literaria.

b) Las reflexiones de Pirandello confirman el vínculo no casual ni extrínseco entre elemento fantástico y elemento humorístico. Se trata de un vínculo que los estudiosos más atentos han advertido como presente de manera continua, aunque a veces sumiso y escondido en los textos fantásticos, comenzando con los de Hoffmann. Se trata de un vínculo que explica, de lo fantástico, junto a los frecuentísimos elementos metatextuales e intertextuales, la potencial carga crítica y destructiva y la función de corrosión de algunas de las ideologías fuertes de la nueva sociedad burguesa: el proyecto de construir, a través de un nuevo conocimiento de sí y de un programa de Bildung, una subjetividad fuerte (a la que lo fantástico responde con la exploración de los temas de la laceración, del doble, de la fragmentación de la experiencia); los procesos de descristianización y laicización de los comportamientos sociales, la lucha contra las supersticiones, la exaltación optimista de la razón y de la ciencia, la formación

palabra, a pesar de que pueda parecer a primera vista una contradicción de términos. Pero es justo así; y, no obstante, siempre he hablado de una actividad especial de la reflexión. [...] La reflexión [...] de la que hablo no es una oposición de lo consciente frente a lo espontáneo; es una especie de proyección de la misma actividad fantástica: nace del fantasma, como la sombra del cuerpo; tiene todas las características de la "ingenuidad" o nacimiento espontáneo; está en el germen mismo de la creación, y emana de ella, de hecho, lo que he llamado el sentimiento del contrario.” 
de una religión de la naturaleza, la atribución idealista a los pueblos y las naciones de un Volkesgeist y a la época histórica de un Zeitgeist (al que lo fantástico responde con el redescubrimiento, en la dimensión literaria, de lo sobrenatural y de lo maravilloso, frecuentemente escondido entre los pliegues de la cotidianidad más banal; con la exploración de lugares exóticos, periféricos, arcaicos; con la búsqueda de las diferencias y de las fragmentariedades sociales e históricas, que no conducen a ninguna unidad; con el análisis de las profundidades más angustiantes, desesperantes, nihilistas del espíritu humano). El haber puesto en relación melancolía y humorismo permite conectar la experiencia de lo fantástico con la historia de los intelectuales en la época de la modernidad y con las corrientes críticas más radicales. Es verdad que Pirandello no practicó verdaderamente el género, sino con intermitencias y de manera excepcional. Pero también es verdad que utilizó muchos temas y procedimientos típicos de la tradición fantástica, revelando una familiaridad sorprendente con ella, sin retomar aquellos modos de manera explícita y mecánica, y adaptándolos continuamente a su mundo narrativo.

c) Es inevitable en este punto, teniendo en cuenta el preciso trasfondo histórico al que se reporta el origen y la disposición propulsiva del modo fantástico, introducir en la discusión otro concepto: el de ironía romántica. Se trata de un concepto que tiene fuertes vínculos con la melancolía y el humorismo, pero que tiene como rasgo específico un elemento filosófico y cognoscitivo, con una precisa dimensión de conocimiento crítico y de distanciamiento intelectual, que son, a mi parecer, también rasgos distintivos, ya sea porque se introducen en las estructuras narrativas o en las tesituras temáticas, de los mejores textos de la tradición fantástica. 


\section{Género y modo}

Se vuelve muy útil, para quien estudia lo fantástico, la distinción entre modo y género literario. Yo conceptúo los modos como procedimientos retóricos-formales, actitudes cognoscitivas y agregaciones temáticas, formas elementales del imaginario históricamente concretas y utilizables por varios códigos, géneros y formas en la realización de los textos literarios y artísticos. Pienso, de hecho, que cada texto está concretamente realizado sobre la base no sólo de un código lingüístico preciso y modelo de género, sino también según una modalidad o la combinación de varias modalidades, similares en esto a los modelos antropológicos de los que hablan estudiosos como Jurij Lotman y Boris Uspenskij.

El modo fantástico, según yo, ha tenido raíces históricas precisas, en la cultura, en los modos de vida, en el imaginario europeo entre el siglo XVIII y el XIX, se ha realizado históricamente en algunos géneros narrativos, dando vida a una tradición textual muy vivaz y difusa. Esta modalidad, pienso, nació no por casualidad en los umbrales de la modernidad, teniendo origen en elementos de la novela gótica inglesa, en la nueva sensibilidad difundida en Europa a fines del XVIII, en nuevos intereses y nuevos conocimientos psicológicos, epistemológicos, científicos, en la crisis de algunas antiguas creencias y certezas de base religiosa, en las nuevas experiencias frente a las complicaciones interiores y exteriores de la vida moderna a las que más tarde Freud dará el nombre de perturbantes o siniestras (Unbeimlich).

Mientras el relato gótico, como género, construyó su tradición utilizando preferentemente el modo novelado y ocasionalmente combinándolo con elementos de la fábula, de lo maravilloso y del horror, el relato fantástico ha dado lugar al descubrimiento de una modalidad literaria, típicamente moderna, que se encuentra también en textos pertenecientes a géneros diversos, incluso en aquellos caracterizados por el más explícito realismo mimético. 


\section{E1 retardo italiano}

No maravilla que la literatura italiana haya visto aparecer los textos fantásticos mucho más tarde que otras literaturas europeas, llegados a nosotros casi siempre por medio de textos franceses (o ingleses, menos frecuentemente alemanes). Todos conocemos los nombres: lo fantástico en Italia aparece en la segunda mitad del siglo XIX y se concentra, aparte de algunas apariciones ocasionales en escritores como Nievo, Fogazzaro y Verga, en la bohemia [scapigliatura ${ }^{6}$ ] piamontesa y milanesa, con Tarchetti y Arrigo Boito, y con alguna presencia menor y periférica, de Di Giacomo a Zena. No se equivocan los críticos que han juzgado, en su conjunto, la producción italiana cualitativamente inferior a la de otras literaturas europeas. Cuando Italo Calvino preparó una bella antología de la literatura fantástica europea (1983), después de haber pensado largamente, decidió no incluir ningún texto italiano. Quizá su juicio fue en aquella ocasión muy severo y seguramente penalizó a un autor de pocos, pero buenos relatos fantásticos como Arrigo Boito ${ }^{7}$ y a un experimentador de temas y de formas, audaz, aunque un poco demasiado acerbo y perseguido por los vencimientos editoriales, como Tarchetti. ${ }^{8}$

¿Cómo se explica el retardo italiano? ¿Con las características peculiares del romanticismo italiano que, si tal vez no se puede decir que no haya existido nunca verdaderamente, como se ha sostenido, ciertamente tuvo profundidad y amplitud de temas inferiores a los

${ }^{6}$ Puede ser útil reproducir aquí parcialmente la aclaración que Juan Díaz de Atauri añade a este término en su traducción al español de mi libro Il fantastico: "movimiento literario y artístico de finales del siglo XIX, cuya denominación tiene su origen en el título de una novela de Carlo Righetti (La scapigliatura e il 6 febbraio, donde scapigliatura se empleaba con un sentido más próximo a la acepción de "desenfreno", inspirado en el término francés bohème). Tuvo auge sobre todo en la Lombardía, especialmente en Milán” (52, nota 33).

${ }^{7}$ De él, se sabe que debe haber escrito otros relatos fantásticos, de títulos bastante intrigantes, que todavía no han sido encontrados.

${ }^{8}$ Son interesantes las consideraciones sobre el modo de trabajar de Tarchetti, entre relatos, poemas, prosas de ocasión, traducciones y verdaderos y propios plagios, en Venutti. 
de otros romanticismos europeos? ¿Con la supervivencia, en muchas zonas de la cultura italiana, junto a motivos de un cristianismo inquieto (lo que explica en parte los casos de Fogazzaro y Zena), de fuertes pervivencias mágicas-paganas, más propias para hacer de algunas regiones de nuestro país los lugares idóneos para servir de trasfondo a historias fantásticas (de ellos se beneficiaron ampliamente Hoffmann, Gautier, Vernon Lee y tantos otros, incluso el Tarchetti visitante de la Calabria), que para inspirar directamente a escritores fantásticos?

Es difícil de decir, y es necesario agregar que en algunos casos, ahí donde no se adelantó la literatura, al menos en la primera parte del siglo XIX, se adelantó en su lugar el teatro en música, verdadero y principal canal de expresión del romanticismo italiano, como ha explicado bastante bien una musicóloga de valía como Adriana Guarnieri Corazzol (2002).

\section{Moderno y Posmoderno}

El modo fantástico ha tenido sus orígenes en el período histórico de la modernidad; y esto ya explica el retardo italiano del que hemos hablado, habiendo nuestro país alcanzado tan tardíamente a mezclarse con los procesos de modernización que, cuando de improviso tuvo que afrontar la posmodernidad y lanzarse a ella con entusiasmo, casi con "desprecio", el proceso de la modernización no estaba del todo completo y quedaban muchas "bolsas" de características predominantemente pre-modernas. Hay quien sostiene que la literatura fantástica había agotado su potencial innovador y original en el xix y que ha sobrevivido sólo en algunas realidades marginales: la Europa Oriental, Sudamérica, etc. No creo que las cosas sean así. Una vez puesto a disposición de nuestro imaginario y de nuestras estrategias representativas, lo fantástico ha sido una presencia fuerte y creativa, ya en el interior del género fantástico verdadero y propio (este sí florecido predominantemente en el siglo XIX), ya en el interior de muchos otros géneros (y no sólo en los de cierta literatura popular, del horror a la fantasy y a la ciencia ficción, 
sino también en textos de tipo novelístico o mimético-realista, en los cuales lo fantástico ha colaborado para crear atmósferas ambiguas y para explorar dimensiones ocultas y perturbadoras), ya en toda una serie de textos típicamente posmodernos, que podemos definir como de neo-fantástico o fantástico revisitado. Entre estos últimos se pueden enumerar, además de escritores de la corriente surrealista europea (de Bretón a Landolfi, incluyendo al último Pirandello, el de Una giornata, sin desdeñar al cine, de los expresionistas a Buñuel), los argentinos Borges, Bioy Casares y Cortázar, los ingleses que vuelven irónicamente sobre la ghost story como Byatt, y tantos otros.

En cuanto a la literatura italiana, para confirmar la superación de todos los retardos y la incluso demasiado entusiasta inmersión en la condición social y cultural posmoderna, bastará recordar el nombre de Antonio Tabucchi, autor de algunos de los más refinados textos de lo neo-fantástico, a medio camino entre ironía y nostalgia. Entre los relatos de Piccoli equivoci senza importanza y del Gioco del rovescio, se hallan varios ejemplos perfectos de revisitaciones posmodernas de lo fantástico. Basta pensar en un relato como "Any where out of the world" (Piccoli equivoci.., 71-81), que Stefano Lazzarin, autor de un utilísimo ensayo sobre el modo fantástico en el que afronta con claridad el problema de la relación entre fantástico del siglo XIx y fantástico del siglo xx, eligió como texto ejemplar para analizar. ¿Qué más ejemplarmente posmoderno, de hecho, que un relato que tiene como acontecimiento perturbador un telefonema "del más allá" y como subtexto de referencia Le Spleen de Paris de Baudelaire?

\section{Obras citadas}

Bleiler, Everett Franklin, ed. Supernatural Fiction Writers: Fantasy and Horror. New York: Scribner's, 1983.

Calvino, Italo, ed. Racconti fantastici dell'Ottocento. Milano: Mondatori, 1983.

Ceserani, Remo. "Le radici storiche di un modo narrativo." En: 
VVAA, La narrazione fantastica. Pisa: Nistri-Lischi, 1983. 7-36. . Il fantastico. Bologna: Il Mulino, 1996 [Existe traducción al español: Lo fantástico. Trad. Juan Díaz de Atauri. Madrid: Visor, 2000].

D’Ancona, Alessandro. Studi di critica e storia letteraria. Bologna: Zanichelli, 1880.

Guarnieri Corazzol, Adriana. "Fantasmi, allucinazioni e seduttrici soprannaturali nell'opera italiana del secondo Ottocento." En Desiderio e trasgressione nella letteratura fantastica. Ed. Michela Vanon Alliata. Venezia: Marsilio, 2002. 21-42.

Jackson, Rosemary. Fantasy. The Literature of Subversion. London-

New York: Methuen, 1981.

Lazzarin, Stefano. Il modo fantastico. Roma-Bari: Laterza, 2000.

Lotman, Jury y Boris Uspensky. Tipologia della cultura. Ed. R. Faccani and M. Marzaduri. Milano: Bompiani, 1975. . Semiotica e cultura. Milano: Ricciardi, 1975.

Pirandello, Luigi. Saggi, poesie, scritti varii. Ed. Manlio Lo VecchioMusti. Milano: Mondadori, 1939.

Schlobin, Roger C. The Literature of Fantasy. A Comprehensive Annotated Bibliography of Modern Fantasy Fiction. New York: Garland, 1979. Sontag, Susan. Under the Sign of Saturn. New York: Farrar, 1980. Starobinski, Jean. Histoire du traitement de la mélancolie des origines à 1900. Basle: Geigy, 1960.

- La mélancolie au miroir: trois lectures de Baudelaire. Paris: Julliard, 1989.

Tabucchi, Antonio. Piccoli equivoci senza importanza. Milano: Feltrinelli, 1985.

. Il gioco del rovescio. Milano: Feltrinelli, 1988.

Todorov, Tzvetan. Introduction à la littérature fantastique. Paris: Seuil, 1970.

Venuti, Lawrence. Translator's Invisibility. A History of Translation. London: Routledge, 1995. 